\title{
PALABRAS COMO ARMAS
}

\author{
Susan Benesch \\ Traducción: Santiago Castellanos Ph.D.
}

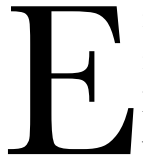

ntre amigos y seguidores, durante su alcoholizada fiesta de cumpleaños número 29, en marzo de 2010, el líder juvenil sudafricano Julius Malema levantó su pulgar derecho, apuntó con su índice como si fuese una pistola y cantó "Dubulu iBhunu" (disparen a los Bóer). La multitud cantó alegremente con él.

Malema cantó Dubulu iBhunu otra vez, pocos días después, en un mitin en la Universidad de Johannesburgo, pero esta vez transmitida por televisión y con traducción al Afrikáans. El término 'Bóer,' que originalmente significaba 'granjero,' era ahora un término despectivo para referirse a los Afrikáner. Cientos de molestos blancos presentaron protestas formales ante un juez quien ordenó a Malema dejar de cantar Dubulu iBhunu hasta que el asunto se decida en los tribunales. Él continuó de todas maneras, aduciendo que solo estaba preservando un viejo himno de la lucha anti-apartheid - un pedazo de herencia cultural que no debe ser tomado en forma literal. Según Malema, él cantaba sobre el sistema de apartheid diseñado por los Afrikáner, pero no alentaba a sus oyentes a dispararlos.

Julius Malema es el fundador del partido político suafricano "Luchadores por la Libertad Económica". Ha sido sentenciado en dos ocasiones por discurso de odio, una en 2010 y otra en 2011. 
Una tormenta de debates siguió en Sudáfrica, especialmente en el internet. Los blancos temían que la canción inspirase a los sudafricanos negros a matar a los granjeros Afrikáner. En años recientes, cientos de hacendados y empresarios blancos habían sido asesinados, en su mayoría en conexión con robos, pero a menudo con una violencia espantosa, a veces con sus esposas y sus hijos. Pero el Congreso Nacional Africano que estaba en el poder defendió a Malema, entonces jefe de su Liga Juvenil, y también a la canción. El vocero del partido, Jackson Mthembu, se hizo responsable a nombre del CNA diciendo que la canción "se cantó por muchos años, incluso antes de que Malema naciera," y que por tanto debe ser entendida en el contexto de la lucha anti-apartheid. La Ministra de Arte y Cultura de Sudáfrica Lulo Xingwana y otros políticos se unieron en su desafío al juez cantando la canción en el aniversario número 31 del ahorcamiento de un luchador anti-apartheid.

La controversia todavía estaba en su apogeo meses después, en febrero de 2011, cuando Bono de U2 realizó un tour por Sudáfrica. Al preguntársele sobre Dubulu iBhuntu, Bono la comparó con las canciones del Ejército Republicano Irlandés que él había cantado con sus tíos cuando era niño. "El asunto es dónde y cuándo cantas dichas canciones," dijo Bono. De hecho, los discursos y las canciones pueden ser poderosos catalizadores para toda clase de acción humana, pero su significado e impacto depende mucho del contexto y de quién está hablando y escuchando.

Afriforum, un grupo Afrikáner de derechos civiles, llevó a Malema a los tribunales debido a la canción. En septiembre de 2011, el juez Collin Lamont la prohibió bajo la ley sudafricana que prohíbe discursos que muestran una clara intención de ser hirientes, de incitar al daño o de promover el odio. Minutos después de que el juez terminara de leer su bien pensado veredicto de una hora, un grupo de jóvenes seguidores de Malema cantaron a voz en cuello Dubulu iBhunu a pocos metros de la puerta del tribunal, tal y como Malema había advertido que lo harían. Los cantantes tuvieron una audiencia en vivo - una fila de policías parados rígidamente con sus cascos antidisturbios. Ni el juez ni la policía pudieron detener la canción.

\section{"Los discursos y las canciones pueden ser poderosos catalizadores para toda clase de acción humana pero su significado e impacto depende mucho del contexto y de quién está hablando y escuchando.'}

En su defensa durante el juicio, Malema dijo que la culpa no era de él sino de los periodistas que habían hecho a los Afrikáners conscientes de la canción al traducir sus palabras. Aunque no logró convencer al juez, Malema sin quererlo señaló un profundo cambio que estaba teniendo lugar en la comunicación alrededor del mundo y que demandaba nuevas políticas, especialmente desde que se evidenciaba que la ley, por sí sola, era inadecuada. 
AfriForum fue fundado el año 2006. En la actualidad, el grupo defensor de derechos civiles cuenta con 167.000 miembros.

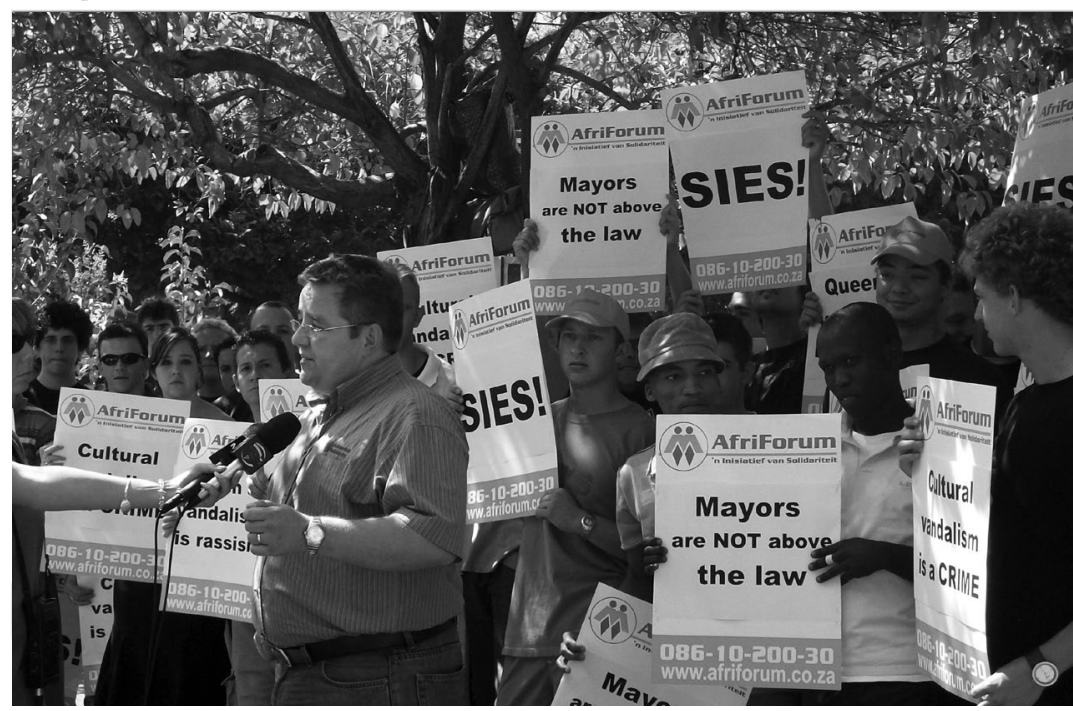

\section{Enseñando miedo y odio}

Las personas son cada vez más conocedoras de ciertas comunicaciones que no habrían escuchado (o leído, o visto) en el pasado, es decir, del lenguaje interno de otras comunidades culturales dispares como las canciones que los miembros de un grupo cantan juntos, los chistes que se dicen unos a otros, las palabras que los líderes usan para reunir a los partidarios para enseñar miedo y odio a otros fuera del grupo, o para inspirar violencia.

Los musulmanes, de Afganistán a Arabia Saudita, conocen que el profeta Mahoma ha sido satirizado (y para ellos, profanado) por caricaturistas en un periódico provincial danés, las feministas descubren páginas de Facebook en las que los hombres se reúnen para intercambiar chistes de violaciones, y los Afrikáners rurales temen que una canción Zulú pudiese provocar violencia contra ellos en la atmósfera racialmente cargada de la Sudáfrica de hoy en día.

Varios factores convergen para influir en diversas audiencias y aumentar su participación en numerosos campos de batalla lingüísticos. En Sudáfrica, un factor primordial fue la caída del apartheid, como lo señaló el Juez Lamont en su fallo sobre Dubulu iBhunu. Desde que Nelson Mandela se convirtió en presidente en 1994, negros y blancos en Sudáfrica han sido forzados a escucharse unos a otros como nunca antes, literal y figurativamente. Personas que "no estaban acostumbradas unas a otras comenzaron a asociarse y a interactuar," a veces produciendo un "conflicto social extremo," observó el Juez. En otros países, las luchas en contra de regímenes 
autoritarios, y a veces su caída, han derrumbado los muros existentes entre grupos cultural o religiosamente dispares. Esto puede provocar una mayor comprensión entre ellos, como en el caso de ciertos cibernautas Chinos Han que han aprendido a escuchar las quejas de los tibetanos por primera vez. Pero también puede conducir al terror, como sucedió con los Cristianos Cópticos en Egipto.

Las migraciones masivas y las fronteras cambiantes han puesto al alcance del oído a comunidades que antes estaban culturalmente separadas unas de otras y que ahora comparten incluso la misma nacionalidad - transformando sociedades que una vez fueron largamente homogéneas en crisoles de diversidad. La comunidad musulmana danesa que reaccionó con indignación a las caricaturas publicadas en 2005, por ejemplo, difícilmente existía hace unas pocas décadas. Y en el mundo entero, el internet, los mensajes de texto y las redes sociales son quizás los motores más grandes de diversificación de audiencias porque permiten que las comunidades se escuchen unas a otras como nunca antes. No es únicamente que las palabras y las imágenes viajan más rápido y llegan más lejos, sino que además traspasan con más ligereza y con más rapidez los límites que la historia ha establecido entre comunidades humanas Incluso las barreras del lenguaje son superadas por medio de la tecnología. Aunque a veces sea peligrosamente imprecisa, la traducción puede ser automática y rápida en la actualidad.

Resaltar la importancia de este cambio es difícilmente una exageración. Desde que nuestros ancestros primitivos aprendieron a hablar, reunirse en grupo y escuchar a alguien que habla - un anciano de la familia, un líder religioso, un comandante militar, o un político - ha sido una práctica universal y común. Quien habla y su audiencia comparten un cuerpo único de conocimiento cultural y de creencias que dan forma a su comprensión del lenguaje que utilizan entre ellos, sea este una película, una caricatura, o un grito en común. Cuando se comunican dentro del grupo, quienes hablan eligen un lenguaje familiar a su propia gente, no a los "otros"-feministas, negros o blancos, la otra tribu, otro partido, o los adherentes a otra religión. Quien habla conoce los miedos particulares de la audiencia, sus quejas, sus referencias históricas - y usa ese conocimiento para construir discursos poderosos.

Debido a que el lenguaje viaja fácilmente entre comunidades, es cada vez menos usual para cualquier líder hablar solo a su propia gente y sin ser escuchado por otros. Algunos, como los caricaturistas daneses, quedaron sorprendidos por la indignación y las violentas respuestas que provocaron. Otros parecen indiferentes o cobardemente satisfechos, como Malema o Terry Jones, el pastor que quemó el Corán en Gainesville, Florida, en marzo de 2011, supuestamente para "castigar" al libro sagrado. Jones persistió, aún después de que el mismo General David Petraeus, entonces comandante estadounidense en Afganistán, así como el Departamento de 
Estado de los Estados Unidos y la Casa Blanca, le pidieron que se abstuviese. La noticia llegó inmediatamente a Afganistán y predeciblemente 22 personas, incluyendo a siete trabajadores extranjeros de las Naciones Unidas, fueron asesinadas por una turba enfurecida en Mazar-i-Sharif.

\section{Audiencias más altas}

Con cada caso bien publicitado, los productores de discursos - sean predicadores, caricaturistas o cantantes - están cada vez más conscientes de que sus palabras o sus imágenes son capaces de llegar a audiencias de diferentes trasfondos culturales y de que serán juzgados de acuerdo a estándares variados. Como el Juez Lamont escribió, después de que Dubulu iBhunu se convirtió en un tema de generalizado furor en Sudáfrica, "nunca más será inocuo."

Las personas que hablan pueden ser inducidas a ser más cautelosas con sus palabras si están conscientes de que serán escuchadas por un grupo más amplio, lo cual presenta oportunidades para nuevas políticas y recomendaciones. Cuando la audiencia no es amplia, puede ser útil diversificarla intencionalmente. Esta es una alternativa a la de prohibir ciertas clases de discurso, lo cual es de por sí una mala opción porque, además de afectar a la libertad de expresión, a menudo no funciona en la práctica.

Kenia vio meses de un creciente discurso inflamatorio en el 2007 cuando los líderes políticos incitaron a sus propias tribus en contra de otras tribus - muy a menudo usando lenguas vernáculas o tribales. En un país con 43 grupos étnicos distintos, casi todos hablan una "lengua materna" además del Swahili o del Inglés, pero nadie puede comprenderlas todas. Al final del 2007, después de una disputada elección presidencial, hubo una explosión de violencia en ciertas partes del país. Más de mil personas fueron asesinadas y cerca de 500,000 fueron desplazadas. Ahora, mientras Kenia se prepara para su próxima elección presidencial, su red de televisión KTN ha experimentado con una técnica de diversificación de audiencias.

Cuando los políticos kenianos dan discursos inflamatorios a sus mismos seguidores y en sus propios lenguajes, hablando con términos que dudarían en usar frente a una audiencia más amplia, KTN a veces transmite tales discursos por televisión nacional, subtitulados en Swahili o en Inglés. La cadena ha decidido diversificar la audiencia como forma de disuadir o avergonzar a aquellos que podrían utilizar discursos inflamatorios en sus propios círculos reducidos. El director de noticias de KTN , Linus Kaikai, dice que aquellos políticos que usualmente utilizan un lenguaje incendiario con sus propios grupos étnicos y en su propia lengua materna, la diversificación de audiencias "hace que les importe más lo que dicen. Tienden a sanear su lenguaje." 
Esta técnica se relaciona con la técnica estándar de defensa de los derechos humanos de nombrar y avergonzar. Aunque los verdaderos trúhanes tal vez no se detengan por las vergüenza, algunos pueden ser influenciados, o incluso puestos en línea, por miembros de su misma comunidad. El CNA, por ejemplo, expulsó a Malema del partido a finales de febrero. Aunque él ya había dado al CNA numerosas razones para ser disciplinado, incluyendo asuntos de corrupción personal y de crítica al Presidente Jacob Zuma, la canción también avergonzó a los líderes del CNA.

\section{Y luego está la ley}

La ley, aunque contundente y pesada para esta tarea, es la principal herramienta para frenar el discurso peligroso sin tropezar con la libertad de expresión. En los últimos 15 años, los tribunales internacionales han condenado a más de una docena de acusados, la mayoría de ellos de Ruanda, por incitación al genocidio, y además han aceptado varias declaraciones de culpabilidad. El Tribunal Criminal Internacional

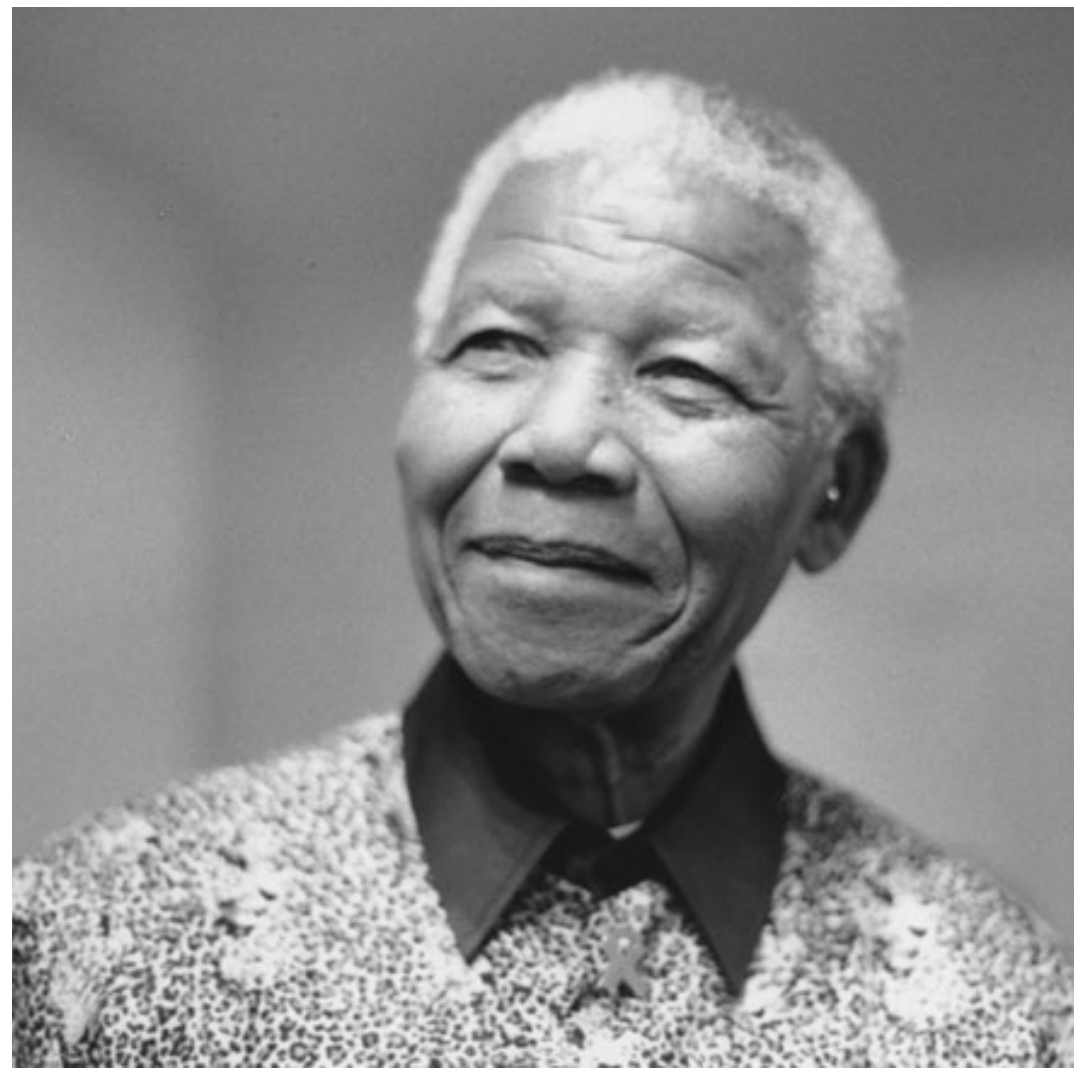

El ex presidente sudafricano, Nelson Mandela, luchó incansablemente por la igualdad de Derechos Civiles entre blancos y negros en su pais, promoviendo de manera pácifica el discurso no violento entre sus seguidores. 
investigó la violencia de 2007-2008 de Kenia y está enjuiciando a cuatro kenianos por crímenes en contra de la humanidad, incluyendo a un difusor de radio cuyo rol se limitaba al discurso - una clara indicación de que el TCI está convencido de la importancia del discurso como catalizador de violencia masiva.

A Joshua arap Sant, el radiodifusor, se le acusa de incitar a la violencia durante su programa matutino con llamadas en KASS FM, una estación de radio en lenguaje Kalenjin que sigue siendo influyente entre los miembros del grupo étnico Kalenjin de Kenia. Si Sang es condenado, o incluso si es absuelto, el caso se convertiría en un referente en el derecho internacional sobre discurso criminal.

El TCI por sí solo habría sido incapaz de manejar el gran universo de discursos que inflaman la tensión y pueden encender la violencia. Además, la mayoría de tales discursos nollega al nivel de los graves crímenes internacionales a los que la jurisdicción del TCI se limita. Se necesita una herramienta de formulación de políticas para trazar la línea entre aquel discurso que debiera ser sancionado y aquel discurso que debe ser tolerado en nombre de la libertad de expresión, no importa lo feo que pudiera ser.

Comunidades diversas nunca podrán ponerse de acuerdo sobre qué tipos de discursos son inherentemente ofensivos. ¿ Un dibujo representando a Mahoma es meramente provocador, divertido, o intolerablemente ofensivo? La ley internacional y las políticas deberían enfocarse en un estrecho pero notable subconjunto - discursosinflamatorios que preceden a la violencia, especialmente a explosiones de violencia masiva, como el genocidio. Antes de tales explosiones, los líderes se dirigen a su grupo con un lenguaje calculado para deshumanizar a otro grupo objetivo. Los propagandistas nazis se refirieron a los judíos como parásitos y plagas, los propagandistas Hutu hablaban de cucarachas al referirse a la gente Tutsi, Slobodan Milosevic describía a los musulmanes como cuervos negros. En cada caso, tal tipo de discurso es el precursor de violencia masiva, especialmente violencia contra poblaciones civiles indefensas.

El Proyecto de Discurso Peligroso ha distinguido las características típicas de los discursos que parecen catalizar precisamente aquellos tipos de violencia masiva y ha desarrollado guías para analizar el nivel de peligro que representa algún particular giro lingüístico: qué tan probable es que conduzca a la violencia en un contexto específico. Este análisis puede aplicarse a cualquier forma de expresión —un dibujo, una fotografía, una película - y no solo a las palabras.

\section{Qué palabras detonan}

Usando únicamente estos cinco criterios, se puede estimar la probabilidad de que el discurso detone violencia en cualquier situación dada: la persona que habla, la audiencia, el discurso mismo, el contexto histórico y social, y los medios de diseminación. 


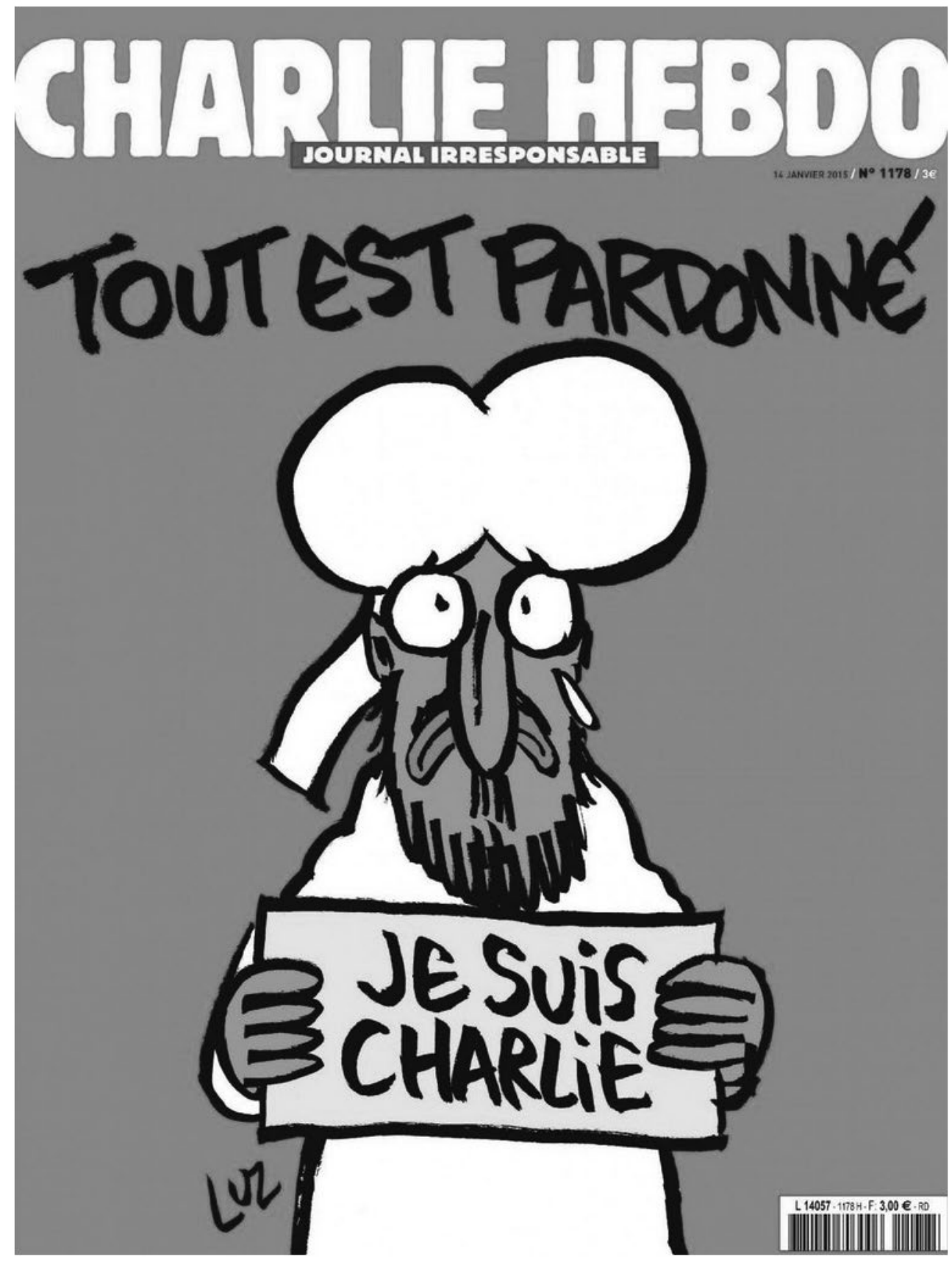

El periódico satítico Charlie Hebdo ha sido objeto de críticas por una supuesta islamofobia a nivel editorial. 
En cada caso, uno o más de esos criterios puede ser especialmente importante. La persona que habla puede tener una gran influencia sobre una audiencia particular, y ciertas audiencias pueden ser especialmente vulnerables debido a sus dificultades económicas, al miedo, o a agravios pre-existentes. Ciertos eventos relacionados con el lenguaje - definidos ampliamente para incluir actos de expresión, tales como quemar un libro - pueden ser particularmente poderosos. En algunos casos, es el último criterio, el modo de diseminación, el que tiene importancia determinante, especialmente cuando tiene lugar a través de nuevos medios. Los mensajes de texto son usados crecientemente para organizar revueltas y masacres en muchos países. Para los jóvenes de naciones en desarrollo, cuyos celulares los vinculan al mundo y les dan un sentido de agencia y de poder, un mensaje como este de 2007 puede aparecer en sus pantallas, cuando la violencia étnica estalló en Kenia:

"No será derramada más sangre inocente Kikuyu. Los asesinaremos aquí mismo, en la ciudad capital. Para hacer justicia, compilen una lista de los ya saben quien de Luo...les daremos números telefónicos para enviar esta información.”

En tal caso, el modo de diseminación fue tan influyente como el contenido.

En el problema de Dubulo iBhunu, Malema era un líder influyente que cantaba esta canción a seguidores jóvenes que sufrían extensas dificultades económicas y todavía estaban en desventaja en comparación con los sudafricanos blancos. Ciertas palabras de la canción comparan a los Boers con perros, deshumanizándolos, por lo que no es difícil interpretar el estribillo, especialmente por los gestos que usa Malema con sus manos, como un llamado al ataque.

Pocos meses después de que el Juez Lamont prohibiera la canción, en abril de 2011, Tokelo Nhlapo, un miembro juvenil de la liga y líder estudiantil de la Universidad de Witwatersrand, dijo a una multitud, "Estoy tentado a cantar esa canción," y luego comenzó a cantar la música prohibida con un nuevo estribillo: "Dubulu Lekgoa," es decir, "disparen a los blancos," acompañado por una entusiasta audiencia estudiantil, toda de pie. 